\title{
"Counting those never bubble over" Estimated prevalence and its determinants of obstetric fistula among childbearing women in 14 African countries: Multilevel Analysis
}

Melsew Setegn Alie ( $\nabla$ melsewsetegn2010@mtu.edu.et )

Mizan-Tepi University

Research Article

Keywords: Obstetric fistula, Fistula, Vesicovaginal fistula, VVF

Posted Date: November 22nd, 2021

DOI: https://doi.org/10.21203/rs.3.rs-1074592/v1

License: (c) (i) This work is licensed under a Creative Commons Attribution 4.0 International License.

Read Full License 


\section{Abstract \\ Background}

Obstetric fistula is a leakage between genital tract and urinary tract and/or between genital tract and rectum. The commonest cause of obstetric fistula is prolonged labour which magnify in the areas of poor prenatal and emergency obstetric care. In Africa, there is poor of quality of obstetric care and poor social support for those who faced fistula. Obstetric fistula shatters the life of the women and the consequence is nasty while multicounty level estimate on the magnitude and determinates of fistula were nil. Multicounty level of estimate of the magnitude of fistula is important to design and fill the gaps of quality of obstetric care and design the appropriate corrective intervention mechanisms of obstetric fistula. Therefore, this study aimed the estimate the magnitude of obstetric fistula and its determinants among childbearing women in 14 Africa countries based on recent demographic and health survey data.

\section{Methods}

Secondary data were used from 14 African demographic and health survey database. The data were extracted based on the objective the study and previous literatures. Data were weighted using sampling weight before any statistical analysis to account the sampling design. STATA version 15 was used for extracting, recoding, and for further multilevel analysis. The appropriateness of multilevel analysis were checked by Median odds ratio (MOR), proportional change in Variance (PCV), Intraclass correlation coefficient (ICC), and Akaike Information Criteria (AIC). Four model was build and the best model was selected based on the smallest Akaike Information Criteria (AIC). Both bivariable and multivariable multilevel analysis was done accordingly. Variables with p-value $\leq 0.05$ declared as statistical significant with outcome variable for the study. The adjusted odds ratio with $95 \%$ confidence interval was used as measure of association.

\section{Results}

The magnitude of obstetric fistula was 0.84 [ $95 \% \mathrm{Cl}: 0.79,0.88$ ]. Maternal age $>=41$ years [AOR $=1.38 ; 95 \%$ $\mathrm{Cl}: 1.01,1.93]$, urban residence [AOR $=0.69 ; 95 \% \mathrm{Cl}: 0.53,0.89]$, women who attended secondary education [AOR=0.59; 95\% Cl: 0.45,0.77], women who attended higher education [AOR=0.40; 95\% Cl: 0.25,0.65], female household head [AOR $=0.78 ; 95 \% \mathrm{Cl}: 0.64,0.95]$, husbands who attended primary education [AOR=0.80; 95\% Cl: 0.65, 0.98], women who give their first birth 16-20years [AOR=0.78; 95\% Cl: 0.66,0.92], $21-25$ years [AOR $=0.66 ; 95 \% \mathrm{Cl}: 0.53,0.84], \geq 26$ years [AOR $=0.67 ; 95 \% \mathrm{Cl}: 0.48,0.92$ ], history of terminating pregnancy $[\mathrm{AOR}=1.51 ; 95 \% \mathrm{Cl}: 1.29,1.77]$ and awareness on fistula $[\mathrm{AOR}=0.35 ; 95 \% \mathrm{Cl}$ : $0.26,0.45$ ) were the determinants of obstetric fistula identified in this study.

\section{Conclusion}


The magnitude of obstetric fistula in 14 African countries were high as compared with the world health organization estimate. Maternal age, residence, educational status, husband's educational status, sex of household head, age at first birth, history of terminating pregnancy and awareness on obstetric fistula were the determinants identified in this study. Therefore, health interventions that reduce the occurrence of obstetric fistula could be designed to address the women who lives in rural area, no formal education, male-headed household, husbands who never attended formal education, and women who had terminated pregnancy should be addressed in advance. Policies and programs of fistula should be tailored the women which characterized as living in rural area, non-educated, young age at first birth and no awareness on fistula as well as male headed households. Evidence based multicounty interventions were highly recommended to eliminate obstetric fistula and to achieve sustainable development goal.

\section{Background}

Obstetric fistula is a leakage between genital tract and urinary tract or leakage between genital tract and rectum commonly caused by prolonged or obstructed labor especially in resource poor countries. It is preventable and treatable while it is ashamed and isolated from the communities. Nearly 2 million of women's globally severed from this preventable disease [1-4]. Fistula is the serious medical disorder, which results continuous leakage of stool or urine. Obstetric fistula is the less intentioned and hidden condition in developing countries. The most marginalized women like poor, young, illiterate and women in remote area are mostly affected one. Obstetric fistula is one of the most visible maternal health indicator and is still exist due to the health system failed to give accessible and quality of maternal health care. It is a public health concern, which has an attention in national and international government in recent time [5-7]. Even though there is no real estimate on obstetric fistula nearly two million women were suffered from this problem in developing countries and fifty to hundred thousand of new cases will occur annually[8].

In sub Saharan Africa this disorder is sever and at least 33,000 new cases were recorded annually, which is huge number, which highly contributes maternal mortality in the region. From the women who give birth annually in sub-Saharan Africa 30,000 to 130,000 of them develop fistula due to obstructed or prolonged labour. In addition fistula is sever in the place where a limited access and use of obstetric care. Obstetric fistula are more prevalent in the area where poor or limited prenatal and intrapartum care[6, 9-12]. The prevalence of obstetric fistula may vary from country to country or from area to area, in all region of the world the pooled prevalence of fistula were 0.29 per 1000 women. By region 1.57 per 100 women in sub Saharan Africa and South Asia, 1.60 per 1000 women of reproductive age in sub Saharan Africa and 1.20 per 1000 in South Asia [13]. The prevalence of fistula in Ethiopia was $0.4 \%$ among reproductive age women [14], in other demographic data analysis the prevalence of fistula in Ethiopia were $0.42 \%$ [15],in other study 6 per 10,000 reproductive age women experienced obstetric fistula [16]. Other study showed $0.12 \%$ of the women experienced obstetric fistula[17], in Afghanistan the prevalence of obstetric fistula was $0.4 \%[18], 1.06 \%$ experienced obstetric fistula in their lifetime [12], in study conducted in Bangladesh the estimated prevalence of obstetric fistula was 1.69 per 1000 ever married women [19], The incidence 
of fistula in rural region of sub-Saharan Africa approximately 33,451 new case annually [20]. In two world region (sub-Saharan Africa and South Asia) there are over 6000 new cases per year[13].

While there is no uniform classification of obstetric fistula. Obstetric cause of fistula can be classified as Vesicovaginal fistula (VVF) and rectovaginal fistula (RVF) and there is iatrogenic types of fistula $[6,7,21]$. The three main cause of obstetric fistula are ischemia of tissue between vagina and urinary tract or rectum, direct tearing of tissues and elective abortion. Even though the causes of fistula are not mutually exclusive, it may occur in complication of delivery and uterine evacuation $[2,22,23]$.

The risk factors of obstetric fistula originated from cultural, social, economic and biological that contributes for obstructed and prolonged labor. Sexual violence also results vaginal fistula [24-26]. Different literatures indicated that factors influencing obstetric fistula were age of marriage, marital status, literacy, parity, duration of labor, type of birth attendance, mode and place of delivery[21, 27-34]. In addition there is health facility related factors like delay in reaching care, delay in decision to seek care, and delay in receiving adequate care [33, 35-37]. Literatures showed that obstetric fistula may results from in different initiators like labor more than 24 hours[24], not attending antenatal care[38], and home delivery[39] while this isnot found in low prevalence areas. Additional factors associated with fistula in previous literatures were early age at pregnancy, short stature, illiteracy, poverty, not attending antenatal care and rural place of residence or living far away $(>3 \mathrm{~km})$ from a health facility[23, 40, 41], duration of labour of $>24$ hours, seeking delivery services after 6 hours of labour onset, taking more than 2 hours to reach a health facility, having none or primary education and being referred to another facility for emergency obstetrics services[42], women who gave birth 10 or more and residence[12] were factors associated with obstetric fistula. The three delays which contributes for obstetric fistula were delay in the making the decision to seek care, delay in arrival at a health facility; and delay in the provision of adequate care[43].

Fistula has a multidimensional consequence on the women who experienced it such as health consequences like incontinence of urine or faecale or both[21], damage of Vulva or thighs[6], social consequences like stigma and marginalization by community[30,44], divorce[35, 45], sexual and reproductive health consequences like loss of fertility or amenorrhea[24,37], absence of sexual intercourse[30, 35, 45], and mental health related consequences like depression[45, 46] were some of the consequences of fistula. Obstetric fistula drop many women's live in dark situation and shatter many women life[7].

The number and/or the magnitude of fistula in the region is the direct reflection of level and quality of perinatal care given by health care system in that specific area. In the area of poor or absent maternal health care, obstetric fistula is high and the treatment is unlikely $[1,5,31]$. Universal access of emergency obstetric care gives the best solution to the problem[7].Therefore, prevention of obstetric fistula is the good ways of saving the women's life since in Africa treating obstetric fistula is like "taking a serpent by the tail". Most of the African countries lacking the quality of fistula care and perinatal care. Therefore understanding the current prevalence is important to design appropriate intervention mechanisms and 
bringing evidence based solution to those resource-limited country. Identifying the factors associated with obstetric fistula is essential to design appropriate intervention approaches and tackle the factors in multicountry situation. In addition, it is important to design appropriate prevention policies and programs that can be all embracing. Therefor this study aimed to estimate the prevalence of obstetric fistula and its determinants among childbearing women in 14 African countries based on the recent demographic and health survey data.

\section{Method}

\section{Data source and population}

This study was analyzed secondary data from the recent Demographic and Health Surveys which contained detailed obstetric fistula for all interviewed childbearing women. Data were obtained and extracted from individual record (IR) file based on the objective and the previous literature finding variables. Demographic and health survey data were collected by a stratified, multi-stage (cluster), random sampling design. The detailed method of data collection were accessed at demographic and health survey database. The source population were all childbearing age women in survey period across the fourteen African countries whereas the study populations were all reproductive age women were included in this survey in the selected Enumeration Areas (EA). The study included all childbearing agewomen found in the selected clusters at least one night before data collection period. All women's who did not give birth before the survey period were excluded from the study. A total of 232,050 reproductive age women were involved in this study.

\section{Variables and measurement}

\section{Dependent variable}

The outcome variable is obstetric fistula where it is a binary variable which a woman who experience obstetric fistula is coded as ' 1 ' for Yes while not experienced obstetric fistula is coded as ' 0 ' for No.

\section{Independent variable}

In this study, both the individual and community level variables were included. The independent variables were age, residence, educational status, husbands educational status, wealth status, sex of household head, media exposure, age at first birth, total number of children, working status, history of terminating pregnancy,and awareness on fistula

\section{Operational definition and description of variables}

\section{Obstetric fistula}

Obstetric fistula among women who had at least one birth in the 5-year period prior to the survey was the outcome of the study which coded as Not experienced obstetric fistula " 0 " and Experienced obstetric 
fistula " $1 "$.

\section{Age of respondents}

Current age of the mother recoded in to four categories with values of " 0 " for < =20, " 1 " for $21-30$," 2 " for $31-40, " 3$ " for >=41 years.

\section{Working status}

Women working status was coded as No "if women who didn't have any work", coded as '0', and Yes "If a woman were working, she might be self-employed, professional or nonprofessional employee or government employed" coded as ' 1 '.

\section{Educational status}

The minimum level of education the mother achieve and it was coded as ' 0 ' for no formal education, as ' 1 ' for primary education, as ' 2 ' for secondary, and as ' 3 ' higher (college and above level of education) .

\section{Wealth status}

Categorized as; poor "if woman was in poorer and poorest household in the DHS database" coded as '0', middle where categorized as middle coded as ' 1 ', and rich "if woman was in richer and richest household" coded as ' 2 '.

\section{Husband's educational status}

It was an education status of the husbands achieve and it was coded as ' 0 ' for no formal education, as ' 1 ' for primary education, as ' 2 ' for secondary education and as ' 3 ' for higher (college and above level of education).

\section{Residence}

The place of residence for the mother was coded as '0'for rural and as ' 1 ' for urban

\section{Media exposure}

a composite variable of frequency of listening radio, watching television and reading newspaper, in which households were said to have media exposure "if they have exposed to either of listening radio or watching television or reading newspaper at least one a week" coded as ' 1 ' and no "if they did not have exposure to all of the above media sources once per week" coded as ' 0 '.

\section{Age at first birth}

According this study age at first birth was categorized as $\leq 15$ year coded as ' 0 ', 16 -20years coded as ' 1 ', 21-25 year coded as ' 2 ' and $\geq 36$ years coded as ' 3 '. 


\section{Parity}

The parity of the women in this study was categorized as nulliparous coded as ' 0 ', $<=4$ parity coded as ' 1 ', $5-8$ parity coded as ' 2 ' and $>=9$ parity coded as ' 3 '.

\section{Sex of household head}

The variable sex of household head was coded as ' 0 ' for male and as ' 1 ' for female in the dataset and we used without change.

\section{Total number of children}

The total number of children in the household was categorized as ' 0 ' for $\leq 3$ child, as ' 1 ' for $4-6$ child, as ' 2 ' for 7-9child, and as ' 3 ' for $\geq 10$ child

\section{Health facility visit}

The women who visit health facility in last 12 months were coded as ' 1 ' as Yes and who did not visit health facility were coded as ' 0 ' as No.

\section{History of terminating pregnancy}

The women who experienced of terminated pregnancy were coded as ' 1 ' for Yes and women who did not experienced terminated pregnancy were coded as ' 0 ' for No.

\section{Awareness on fistula}

The women who aware on the fistula were coded as ' 1 ' for Yes and the women who did not aware on fistula were coded as ' 0 ' for No used as dataset coded.

\section{Data analysis}

The variables of the study were extracted from individual record (IR) file dataset using STATA version 15. Before any analysis, the data were weighted using sampling weight to account the sampling design. After the data were cleaned, categorized, coded and weighted by using STATA, the author explored the descriptive statistics by using the frequencies and percentages of data and presented by using tables. Intraclass Correlation Coefficient (ICC), proportional change in variance (PCV) and median odds ratio (MOR) were calculated for the appropriateness of multilevel logistic regression analysis and checking the presence of clustering. We used the ICC value greater than $5 \%$ to consider a variation of magnitude of fistula across the cluster. Significant clustering was found therefore multilevel logistic regression were more appropriate. Four models were built; null model (model 0) only dependent variable, model 1 dependent variable and community level factors, model 2 dependent variable and individual level variable and the final model (model 3 ) was dependent variable and both community level and individual level factors. The best model was selected by comparing the AIC level and the model with smallest Akaike 
Information Criteria (AIC) is the best-fitted model. Therefore, a model with a smallest Akaike Information Criteria (AIC) value was selected and all interpretations and inferences were made based on this model. After selecting the best-fitted model, bivariable and multivariable multilevel logistic regression was done to determine the determinants of magnitude of fistula in 14 African countries. Both bivariable and multivariable multilevel analysis was done accordingly. Variable in bivariable analysis with $p$-value $<0.25$ were selected in multivariable multilevel analysis. Finally, P-value $\leq 0.05$ to declare statistically significant variables. The level of association were declared by odds ratio and $95 \%$ confidence interval.

\section{Result}

\section{Characteristics of the study population}

Among the study participants more than one third, 83,857[36.14\%] of them were in the age category of 21-30 years. Of the total respondents most, 154,491[66.58\%] were residing in rural area. Nearly thirty nine percent [38.74\%] of the study participants were not follow formal education in their last time. More than half of the study participants had their own work during the data collection time (125, 6749 [54.16\%]). Concerning the educational status of the husbands, forty four percent of the study. Regards to the wealth status of the study participants showed that more than one third [36.34\%] were poor wealth status. Majority of the study, 177,912 [76.67\%] of the households were male headed. More than half [52.05\%] of the study participants were there is no media exposure in the previous time (Table 1). 
Table 1

Socio-demographic and economic distribution of the study participants in 14 African countries

\begin{tabular}{|lcc|}
\hline Variables & Frequency & Percentage (\%) \\
\hline Maternal age & & \\
\hline$<=20$ years & 58,930 & 25.40 \\
\hline $21-30$ & 83,857 & 36.14 \\
\hline $31-40$ & 58,596 & 25.25 \\
\hline >=41 & 30,667 & 13.22 \\
\hline Residence & & \\
\hline Urban & 77,559 & 33.42 \\
\hline Rural & 154,491 & 66.58 \\
\hline Educational status & & \\
\hline No education & 89,890 & 38.74 \\
\hline Primary education & 68,061 & 29.34 \\
\hline Secondary education & 61,357 & 26.45 \\
\hline Higher education & 12,702 & 5.47 \\
\hline Maternal working status & \\
\hline Working & 125,674 & 54.16 \\
\hline Not working & 106,376 & 45.84 \\
\hline Husband's educational status & \\
\hline No education & 67,003 & 44.28 \\
\hline Primary education & 36,996 & 24.45 \\
\hline Secondary education & 35,215 & 23.27 \\
\hline Higher education & 12,097 & 7.99 \\
\hline Wealth status & & \\
\hline Poor & 84,322 & 36.34 \\
\hline Middle & 45,045 & 19.41 \\
\hline Rich & 102,684 & 44.25 \\
\hline Sex of household head & & \\
\hline
\end{tabular}




\begin{tabular}{|lll|}
\hline Variables & Frequency & Percentage (\%) \\
\hline Male & 177,912 & 76.67 \\
Female & 54,138 & 23.33 \\
\hline Media exposure & & \\
Yes & 111,264 & 47.95 \\
No & 120,786 & 52.05 \\
\hline
\end{tabular}

\section{Obstetric and reproductive health characteristics}

Among the study participants who were involved in this study, nearly half, 107,722 [46.42\%] were parity of less than or equal to four. The women who had less than or equal to two child were $128,595[55.42 \%]$ in this study. The women's age at first birth were in the age category of $16-20$ year were $95,068[40.97 \%]$. Majority [83.66\%] of the study participants were visit the health facility in the past 12 month. Eighty eight percent [88.42] of the study participants were never terminated their pregnancy in their own lifetime. With the regards to the awareness of fistula most [65.88\%] of the study participants were had no awareness regarding to fistula (Table 2 ). The prevalence of obstetric fistula among childbearing age women were 0.84 [95\% Cl: $0.79,0.88]$. 
Table 2

Obstetric and reproductive health

characteristics of the study participants in 14 African countries.

\begin{tabular}{|c|c|c|}
\hline Variables & Frequency & Percentage (\%) \\
\hline \multicolumn{3}{|l|}{ Parity } \\
\hline Nulliparous & 61,678 & 26.58 \\
\hline$<=4$ parity & 107,722 & 46.42 \\
\hline 5-8 parity & 52,015 & 22.42 \\
\hline$>=9$ parity & 10,635 & 4.58 \\
\hline \multicolumn{3}{|c|}{ Total number of children } \\
\hline$\leq 2$ child & 128,593 & 55.42 \\
\hline 3-5child & 72,764 & 31.36 \\
\hline 6-9 child & 29,374 & 12.66 \\
\hline$\geq 10$ child & 1,319 & 0.57 \\
\hline \multicolumn{3}{|c|}{ Age at first birth } \\
\hline$<=15$ year & 85,955 & 37.04 \\
\hline 16-20 year & 95,068 & 40.97 \\
\hline $21-25$ year & 38,661 & 16.66 \\
\hline$>=26$ year & 12,369 & 5.33 \\
\hline \multicolumn{3}{|c|}{ Health facility visit in last 12 months } \\
\hline Yes & 37,927 & 16.34 \\
\hline No & 194,123 & 83.66 \\
\hline \multicolumn{3}{|c|}{ Terminated pregnancy } \\
\hline Yes & 26,865 & 11.58 \\
\hline No & 205,185 & 88.42 \\
\hline \multicolumn{3}{|c|}{ Awareness on fistula } \\
\hline Yes & 79,184 & 34.12 \\
\hline No & 152,866 & 65.88 \\
\hline \multicolumn{3}{|c|}{ Experienced obstetric fistula } \\
\hline Yes & 1,948 & 0.84 \\
\hline
\end{tabular}

Page $11 / 24$ 


\begin{tabular}{|llll|}
\hline Variables & Frequency & Percentage (\%) \\
\hline No & 230,102 & 99.16 \\
\hline
\end{tabular}

\section{Random effect Analysis}

The appropriateness of multilevel analysis of the study was done before the actual multilevel analysis of the study. Multilevel analysis is necessary because there is a significant clustering of fistula in this DHS data. The intraclass correlation coefficient (ICC) was $28.33 \%$ means $28.33 \%$ of the variability in magnitude of fistula among reproductive age women were attributed to the clusters. The median odds ratio (MOR) value of the null model 2.96 also indicates the presence of variation in unmet need for family planning between clusters. It means if we randomly select households from different clusters, those households at the cluster with higher fistula had 2.96 times higher chance of having fistula compared to their counter parts. As shown in Table 3, model 3 has the smallest Akaike Information Criteria (AIC $=15733.10$ ) as compared to random intercept only model or null model (AIC=21181.75), model with only community-level factors (AIC=21179.48) and model with only individual-level factors ( $\mathrm{AIC}=16051.09$ ) (Table 3). In addition the proportional change in variance (PCV) increases from $0.77 \%$ (null model) to $22.1 \%$ (model 3), indicating that mode 3 were the best explains the variability of fistula among the clusters. Therefore, this model is the best-fitted model for the data because it has the smallest AIC as compared to the rest models. So interpretation and reports were made based on this model.

Table 3

Model comparison and random effect analysis of the study conducted in 14 African countries based on DHS data, 2021

\begin{tabular}{|lllll|}
\hline Parameter & Null model $\mathbf{0}$ & Model 1 & Model 2 & Model 3 \\
\hline ICC & $28.33 \%$ & $28.2 \%$ & $26.40 \%$ & $26.2 \%$ \\
\hline Variance & $1.31[1.09,1.55]$ & $1.3[1.10,1.54]$ & $1.18[0.98,1.42]$ & $1.02[1.08,1.54]$ \\
\hline MOR & 2.96 & 2.94 & 2.81 & 2.61 \\
\hline PCV & Ref. & 0.77 & 9.9 & 22.1 \\
\hline Model fitness & & & \\
\hline AIC & 21181.75 & 21179.48 & 16051.09 & 15733.1 \\
\hline
\end{tabular}

\section{Determinants of obstetric fistula}

In the final model(model 3) both individual and community-level variables were added to the model for multilevel analysis, of which maternal age, maternal educational status, residence, husbands educational status, sex of household head, age at first birth, history of terminating pregnancy and awareness on fistula were significantly associated with obstetric fistula in 14 African countries (Table 4). The odds of obstetric fistula among women whose age group of $>=41$ years were 1.38 [AOR=1.38; 95\% Cl: 1.01, 1.93] times more likely as compared to age group of less than or equal to 15 year. The women who live in 
urban area were $31 \%$ [AOR=0.69; $95 \% \mathrm{Cl}: 0.53,0.89]$ less likely experienced obstetric fistula as compared with women's in rural area. The other predictors of obstetric fistula were educational status of the women. The women who attended secondary education were $41 \%$ [AOR=0.59,95\% Cl:0.45,0.77] less likely experienced obstetric fistula as compared with those women who never attended formal education. The odds of fistula among the women's who attended higher education were $60 \%$ [AOR $=0.40 ; 95 \% \mathrm{Cl}: 0.25$, $0.65]$ less likely as compared with the women who never attended formal education. The women's husband educational status were the other predictors of fistula in Africa. The odds of obstetric fistula among husbands who attended primary education were $20 \%$ [AOR $=0.80 ; 95 \% \mathrm{Cl}: 0.65,0.98]$ less likely as compared with those women whose husband never attended formal education.

Female headed households were $22 \%$ [AOR $=0.78 ; 95 \% \mathrm{Cl}: 0.64,0.95$ ) less likely experienced fistula as compare to the household headed by male. The odds of obstetric fistula were $22 \%$ [AOR=0.78; $95 \% \mathrm{Cl}$ : $0.66,0.92], 34 \%$ [AOR=0.66; $95 \% \mathrm{Cl}: 0.53,0.84], 33 \%$ [AOR=0.67; 95\% Cl: $0.48,0.92$ ] less likely among women's who give first birth at age of 16-20 years, 21-25 years, $\geq 26$ years as compared with women's who give their first birth less than or equal to 15 years respectively. The odds of fistula among the women who had history of terminating pregnancy were $1.51[\mathrm{AOR}=1.51,95 \% \mathrm{Cl}: 1.29,1.77]$ times more likely experienced fistula as compared with those who did not have any experience of terminating pregnancy. The other important determinants of obstetric fistula were awareness towards fistula. The odds of obstetric fistula was $65 \%$ [AOR=0.35; $95 \% \mathrm{Cl}: 0.26,0.45]$ less likely among women who had awareness on fistula than the women who had no any awareness on obstetric fistula (Table 4). 
Table 4

Determinants of obstetric fistula among reproductive age women in 14 African country in, 2021.

\begin{tabular}{|c|c|c|c|c|c|}
\hline $\begin{array}{l}\text { V } \\
\text { Variables }\end{array}$ & Category & $\begin{array}{l}\text { Model } 0 \\
\text { (Null) }\end{array}$ & $\begin{array}{l}\text { CMode } 1 \\
\text { AOR }[95 \% \mathrm{Cl}]\end{array}$ & $\begin{array}{l}\text { Mode } 2 \\
\text { AOR[95\% Cl] }\end{array}$ & $\begin{array}{l}\text { Model } 3 \\
\text { AOR[95\% Cl] }\end{array}$ \\
\hline \multirow[t]{4}{*}{ Maternal age } & $<=20$ & & & 1 & 1 \\
\hline & $21-30$ & & & $1.08[0.84,1.38]$ & $1.05[0.82,1.34]$ \\
\hline & $31-40$ & & & $1.24[0.91,1.68]$ & $1.18[0.82,1.34]$ \\
\hline & $>=41$ & & & $1.43[1.03,2.01]$ & $1.38[1.01,1.93]$ \\
\hline \multirow[t]{4}{*}{ Educational status } & No education & & & 1 & 1 \\
\hline & $\begin{array}{l}\text { Primary } \\
\text { education }\end{array}$ & & & $0.85[0.69,1.04]$ & $0.85[0.7,1.03]$ \\
\hline & $\begin{array}{l}\text { Secondary } \\
\text { education }\end{array}$ & & & $0.61[0.46,0.80]$ & $\begin{array}{l}0.59[0.45, \\
0.77\end{array}$ \\
\hline & $\begin{array}{l}\text { Higher } \\
\text { education }\end{array}$ & & & $0.44[0.27,0.71]$ & $\left.\begin{array}{l}0.40[0.25 \\
0.65\end{array}\right]$ \\
\hline \multirow[t]{2}{*}{ Residence } & Rural & & 1 & & 1 \\
\hline & Urban & & $0.9[0.77,0.98]$ & & $0.69[0.53,0.89]$ \\
\hline \multirow{2}{*}{$\begin{array}{l}\text { Maternal working } \\
\text { status }\end{array}$} & Working & & & $1.09[0.93,1.27]$ & $1.08[0.93,1.27]$ \\
\hline & Not working & & & 1 & 1 \\
\hline \multirow{4}{*}{$\begin{array}{l}\text { Husbands } \\
\text { educational status }\end{array}$} & No education & & & 1 & 1 \\
\hline & $\begin{array}{l}\text { Primary } \\
\text { education }\end{array}$ & & & $0.81[0.65,1.00]$ & $\begin{array}{l}0.80[0.65, \\
0.98]^{2}\end{array}$ \\
\hline & $\begin{array}{l}\text { Secondary } \\
\text { education }\end{array}$ & & & $0.87[0.66,1.15]$ & $0.81[0.61,1.06]$ \\
\hline & $\begin{array}{l}\text { Higher } \\
\text { education }\end{array}$ & & & $1.44[1.01,1.96]$ & $1.37[0.99,1.89]$ \\
\hline \multirow[t]{3}{*}{ Wealth status } & Poor & & & 1 & 1 \\
\hline & Middle & & & $1.05[0.84,1.31]$ & $1.02[0.82,1.27]$ \\
\hline & Rich & & & $1.17[0.94,1.46]$ & $1.08[0.86,1.37]$ \\
\hline \multirow{2}{*}{$\begin{array}{l}\text { Sex of household } \\
\text { head }\end{array}$} & Male & & & 1 & 1 \\
\hline & Female & & & $0.83[0.66,1.03]$ & $0.78[0.64,0.95]$ \\
\hline \multirow[t]{2}{*}{ Media exposure } & Yes & & & $0.91[0.78,1.07]$ & $0.87[0.75,1.01]$ \\
\hline & No & & & 1 & 1 \\
\hline
\end{tabular}




\begin{tabular}{|c|c|c|c|c|c|}
\hline $\begin{array}{l}\text { V } \\
\text { Variables }\end{array}$ & Category & $\begin{array}{l}\text { Model } 0 \\
\text { (Null) }\end{array}$ & $\begin{array}{l}\text { CMode } 1 \\
\text { AOR[95\% Cl] }\end{array}$ & $\begin{array}{l}\text { Mode } 2 \\
\text { AOR[95\% Cl] }\end{array}$ & $\begin{array}{l}\text { Model } 3 \\
\text { AOR[95\% Cl] }\end{array}$ \\
\hline \multirow[t]{4}{*}{ Parity } & nulliparous & & & 1 & 1 \\
\hline & $<=4$ parity & & & $1.39[0.97,2.00]$ & $1.44[1.01,2.06]$ \\
\hline & 5-8 parity & & & $1.25[0.81,1.92]$ & $1.32[0.87,2.00]$ \\
\hline & $>=9$ parity & & & $1.17[0.71,1.91]$ & $1.22[0.76,1.98]$ \\
\hline \multirow[t]{4}{*}{ Age at first birth } & $<=15$ year & & & 1 & 1 \\
\hline & $16-20$ year & & & $0.81[0.68,0.97]$ & $\begin{array}{l}0.78[0.66, \\
0.92\end{array}$ \\
\hline & 21-25 year & & & $0.69[0.54,0.88]$ & $0.66[0.53,0.84]$ \\
\hline & $>=26$ year & & & $0.65[0.46,0.92]$ & $0.67[0.48,0.92]$ \\
\hline \multirow{4}{*}{$\begin{array}{l}\text { Total number of } \\
\text { children }\end{array}$} & $\leq 2$ child & & & 1 & 1 \\
\hline & 3-5child & & & $0.96[0.8,1.15]$ & $0.97[0.81,1.17]$ \\
\hline & 6-9 child & & & $0.85[0.65,1.12]$ & $0.86[0.65,1.13]$ \\
\hline & $\geq 10$ child & & & $0.86[0.44,1.62]$ & $0.89[0.47,1.69]$ \\
\hline \multirow[t]{2}{*}{ Health facility visit } & Yes & & & $1.14[0.94,1.37]$ & $1.14[0.96,1.36]$ \\
\hline & No & & & 1 & 1 \\
\hline \multirow{2}{*}{$\begin{array}{l}\text { History of } \\
\text { terminating } \\
\text { pregnancy }\end{array}$} & Yes & & & $1.54[1.31,1.82]$ & $1.51[1.29,1.77]$ \\
\hline & No & & & 1 & 1 \\
\hline \multirow{2}{*}{$\begin{array}{l}\text { Awareness on } \\
\text { fistula }\end{array}$} & Yes & & & $0.37[0.28,0.48]$ & $0.35[0.26,0.45]$ \\
\hline & No & & & 1 & 1 \\
\hline
\end{tabular}

\section{Discussion}

Obstetric fistula has devastating consequences on the live of the women and it shatters the women's life. This problem eliminated from developed nation while it continuously affects the poorest of the poor[47, 48]. Previously obstetric fistula were not give a full attention in maternal and reproductive health arena [49-53]. Even though UNFPA plan to end fistula [48] there is a limited study conducted with nationally representative data at multi-country level. Therefore, this study aimed to estimate the magnitude and its determinants of obstetric fistula in 14 African countries. The current study finding showed that the magnitude of fistula among childbearing women were 0.84 [95\% Cl: $0.79,0.88$ ]. According to world health organization estimate suggested that 3 out of 1000 women of reproductive age women were experienced fistula which is lower than the current study estimate[54]. In addition, this finding is lower than the pooled 
analysis study in Sub Saharan Africa that indicated that the prevalence of fistula was 1.60 and South Asia, 1.20[13] and the study conducted in Ethiopia, which indicated that the lifetime prevalence of obstetric fistula was 1.06[12] and South India [17]. This variation could be due to the variation in the quality of maternal health care among the countries and the difference in the quality of obstetric care services in those regions with the current study area. This implies that universal access of quality of maternal care could eliminate obstetric fistula. Prenatal care, skill birth attendants and access emergence obstetric care has a great effort to prevent obstetric fistula[55].The other possible justification of this variation could be UNFPA and other national and international organization gives an emphasis to end fistula which could be lower the current magnitude of the study. Specifically the study conducted in South India was before the action of to end fistula and before the start of sustainable development goal which focus on maternal health improvement and reduction of maternal mortality.

While the current study finding higher than the study conducted in Ethiopia[15-17], Afghanistan[18], Bangladesh[19], Rajasthan, India[56] and rural Maharashtra[57]. This could be due to variation in intervention and access of emergency obstetric care services. The current study was multi-country and nationally representative while previous study conducted in single area with small sample size, which may lower the magnitude. Specifically in Maharashtra, India, more than half study participants had formal education and majority of them were economically active since fistula are common among poor and illiterate women. The other possible reason could be there is variation in social support and burden of obstructed labor across the countries.

This study also identified the determinants of obstetric fistula in African country. The determinants identified were maternal age, educational status of the women, residence, husband's educational status, sex of the household head, age at first birth, history of terminating pregnancy and awareness on fistula. The odds of obstetric fistula among older women (age $>=41$ ) were 1.38 times more likely experienced fistula as compared with the women age less than or equal to 20 years. This finding was comparable with the study conducted in Uganda which showed that the odds of obstetric fistula were increased at the older age[58] and the study conducted in India which indicated that the occurrence of fistula were more common above the age of 29 years[59]. This could be due to the women may bear macrosomic infant when age increases[60] which could contributes obstructed labor and fistula. The other possible reason could be the women's at older age decreased health seeking behaviour and reluctant to take maternal health services like antenatal care and skill birth delivery.

The risk of experiencing obstetric fistula among the women who had secondary and higher education were $41 \%$ and $60 \%$ less likely as compare with the women who never attended formal education respectively. This finding is comparable with the study conducted in Kenya which showed that women who never attended formal education were at risk of obstetric fistula[59], in study conducted in India[56], in another study conducted rural community showed in poor educational level women obstetric fistula were more prevalent[61]. In other study conducted in north- eastern Nigeria indicated that illiteracy was one of the major risk factors for obstetric fistula[23] and in study conducted in Cameroon indicated that poor educational level women were associated with more experienced obstetric fistula[22]. This could be 
due to maternal educational status had a net effect on maternal health services utilization[62] and had positive association with maternal health service use which can leads to reduce risk of obstetric fistula. The other possible reasons could be in less educated women maternal health service utilization is lower[63] which could elevate the risk of fistula. This could be due to the increased women's health seeking behaviour and educated women could have an increased literacy level. The other possible reason could be educated women could be more in use of contraceptive, skilled delivery and deciding to take health services.

The odds of experiencing obstetric fistula among urban residence were $31 \%$ less likely as compare with the women who live in rural area. This finding is comparable with the study conducted in Cameroon [22], in Ethiopia [15], Zambia [24], West Africa[64]), north-eastern Nigeria[23], and in Ethiopia[65] which indicated that rural place residence were more risk for obstetric fistula. This could be due to maternal health service utilization is lower among women living in rural area [63] which could increase the risk of obstetric fistula. Geographical access to health facility is one of the factor to address universal access of maternal health services[66] which could be contribute the risk of fistula. In rural area, there could be long distance and low quality of service that lower maternal health service usage[67] which may accelerate the occurrence of fistula. This could be due to the lower access to emergence obstetric care and other maternal health services like ANC and skilled delivery. The other possible reason could be traditional practices like FGM and sexual violence may common in rural areas. This implies that critically see the maternal health services and community value on women's health is important to save the women's from shattering of their live.

Husband's educational status were one of the determinate for obstetric fistula. The odds obstetric fistula among women whose husbands attended primary education were $20 \%$ less likely as compare the women's husband never attended formal education. The husbands contribute to the maternal health service use[68] which can improve the risk of experiencing obstetric fistula. This could be partners/husbands educational status were less likely associated with obstructed labor[69] which is main risk for obstetric fistula. This could be due to increased husbands support to take maternal health service, improve the intake of health services and support his wife to take skilled delivery and antenatal care. This implies that husband's education could improve the women's future life from abject. The risk of obstetric fistula were lower among female-headed households as compare with male-headed household. The odds of obstetric fistula among the household headed by female were $22 \%$ less likely as compared with the household headed by male. This could be due to female headed household could be more likely receive maternal health services than the male headed households do[70]. This could be the women able to access and control resource which can cover the service and transport cost to take maternal health services. The other possible reasons for this could be the women's autonomy to decide for maternal health services are easy and they could reduce their risk of obstetric fistula.

The odds of obstetric fistula among the women who give their first birth at the age of 16-20 years, 21-25 years, and $>=26$ years were $22 \%, 34 \%$ and $33 \%$ less likely as compare with the women who give birth less than or equal to 15 years respectively. This finding were comparable with the study conducted in 
Ethiopia[65],Tanzania[71], and India[59] which showed that early childbearing were significantly associated with obstetric fistula. This could be due to physically maturity is the main factor for the occurrence of fistula[59]. This could be due to younger and early adult age women were immature pelvis and more at risk of obstructed labor that results obstetric fistula. Other possible reason could be those younger and early adult age girls and women had poor in maternal health service utilization.

The women who had history of terminating pregnancy were 1.51 times more likely at risk of developing obstetric fistula as compare to the women who never experience obstetric fistula. This finding were comparable with the study conducted in Uganda showed that induced abortion is one of the attributes of fistula[72]. This could be due to low access of obstetric care and poor quality of care that results to obstetric fistula. The other possible reasons could be due to poor/limited access of prenatal care of the women. The other determinants of obstetric fistula were awareness towards fistula. The odds of experiencing fistula among aware women were $65 \%$ less likely as compare with those women who had no awareness on fistula. This could be better knowledge on the problem able to prevent from the occurrence[2]. This could be due to understanding of the women regarding fistula consequences that could set early prevention method for it.

\section{Conclusion}

The magnitude of obstetric fistula were $0.84 \%$ higher as compare to world health organization estimate which showed the occurrence of fistula were 3 per 1000 women. The determinants of obstetric fistula identified in this study were maternal age $>=41$, residence, women who attended secondary education, women who attended higher education, female household head, husbands who attended primary education, women who give their first birth 16-20years, 21-25 years, $\geq 26$ years, history of terminating pregnancy and awareness on fistula. The sun should never rise twice in one glob for the women therefore national and international organization could work to decrease the risk of fistula. Programs and policy should be design to address those women older age, younger age at first birth male-headed households, women who never attended formal education and had no awareness on fistula. In the long run high level of education of women, increasing age at first birth, and increased awareness on fistula could reduce the risk of experiencing obstetric fistula.

\section{Abbreviations}

AOR

Adjusted odds ratio

AIC

Akaike Information Criteria

$\mathrm{Cl}$

Confidence interval

DHS

Demographic and health survey 
Individual record

ICC

Intraclass Correlation Coefficient

PCV

proportional change in variance

MOR

median odds ratio

RVF

rectovaginal fistula

UNFPA

United Nations Population Fund;

VVF

Vesicovaginal fistula

\section{Declarations}

\section{Consent for Publication}

Not applicable

\section{Ethics approval and consent to participant}

A waiver of written informed consent was secured from Demographic and Health Surveys (DHS) program data archivists to download the dataset for this study. After the data were downloaded from the measure DHS website the research of this study will maintain the confidentiality of the data. Since it was based on secondary data, which was publicly available, ethical approval was not required. However, we accessed the data set from the DHS website (https://dhsprogram.com/ ) through registering or online requesting. The DHS data were conducted in accordance with the Declaration of Helsinki.

\section{Data Availability statement}

The datasets analyzed during the current study are available from the demographic and health survey dataset with the reasonable request. The author included all result-based data within the manuscript and the data set can be accessed online from www.measuredhs.com/data

\section{Competing interest}

The author declare that they have no competing interests. 


\section{Funding}

The author did not receive any fund for this research.

\section{Authors contribution}

MS involved in the conception of the study. MS involved in the conceptualized, design, data processing and accuracy, analysis and interpretations of the findings. MS prepared the draft of the manuscript. The author read and approved the final manuscript.

\section{Acknowledgement}

The authors would like to acknowledge DHS for providing the data analyzed in this study.

\section{References}

1. HARMS WC: OBSTETRIC FISTULA. In.: UNFPA; 2012.

2. Tebeu PM, Fomulu JN, Khaddaj S, de Bernis L, Delvaux T, Rochat CH: Risk factors for obstetric fistula: a clinical review. International urogynecology journal 2012, 23(4):387-394.

3. Jokhio A, Rizvi R, Rizvi J, MacArthur C: Prevalence of obstetric fistula: a population-based study in rural P akistan. BJOG: An International Journal of Obstetrics \& Gynaecology 2014, 121(8):10391046.

4. Maheu-Giroux M, Filippi V, Samadoulougou S, Castro MC, Maulet N, Meda N, KirakoyaSamadoulougou F: Prevalence of symptoms of vaginal fistula in 19 sub-Saharan Africa countries: a meta-analysis of national household survey data. The Lancet Global Health 2015, 3(5):e271-e278.

5. De Bernis L: Obstetric fistula: guiding principles for clinical management and programme development, a new WHO guideline. International Journal of Gynecology \& Obstetrics 2007, 99:S117S121.

6. Wall LL, Arrowsmith SD, Briggs ND, Browning A, Lassey A: The obstetric vesicovaginal fistula in the developing world. Obstetrical and Gynecological Survey 2005, 60(7):S3.

7. BADLANI G, WALL L: Fistulas in the Developing World. Health Publication Ltd 2009, 18:1419-1458.

8. Yangzom K: Campaign to End Fistula. Nepal Journal of Obstetrics and Gynaecology 2011, 6(1):1-2.

9. Vangeenderhuysen C, Prual A, Ould el Joud D: Obstetric fistulae: incidence estimates for subSaharan Africa. International Journal of Gynecology \& Obstetrics 2001, 73(1):65-66.

10. UNFPA E: Obstetric fistula needs assessment report: Findings from nine African countries. New York. UNFPA EngenderHealth 2003.

11. Tinuola F, Okau A: Perceived causes of obstetric fistula: data from women of reproductive age in Nigeria. Eur J Soc Sci 2009, 10:36-44. 
12. Biadgilign S, Lakew $Y$, Reda AA, Deribe K: A population based survey in Ethiopia using questionnaire as proxy to estimate obstetric fistula prevalence: results from demographic and health survey. Reproductive health 2013, 10(1):1-8.

13. Adler A, Ronsmans $C$, Calvert C, Filippi V: Estimating the prevalence of obstetric fistula: a systematic review and meta-analysis. BMC pregnancy and childbirth 2013, 13(1):1-14.

14. CSACE I: Ethiopia demographic and health survey 2016. Addis Ababa, Ethiopia, and Rockville, Maryland, USA: CSA and ICF 2016.

15. Gedefaw G, Wondmieneh A, Getie A, Bimerew M, Demis A: Estimating the Prevalence and Risk Factors of Obstetric Fistula in Ethiopia: Results from Demographic and Health Survey. International Journal of Women's Health 2021, 13:683.

16. Ballard K, Ayenachew F, Wright J, Atnafu H: Prevalence of obstetric fistula and symptomatic pelvic organ prolapse in rural Ethiopia. International urogynecology journal 2016, 27(7):1063-1067.

17. Zeleke BM, Ayele TA, Woldetsadik MA, Bisetegn TA, Adane AA: Depression among women with obstetric fistula, and pelvic organ prolapse in northwest Ethiopia. BMC psychiatry 2013, 13(1):1-5.

18. Ahmad KM SK, Bahram AA.: Prevalence of obstetric fistula among women of reproductive age in six provinces of Afghanistan. Social and health development program (SHDP) 2011.

19. Walz NK FM, Begum A, Sultana N, Sarker S, Faisel AJ. Engender Health.: Situation analysis of obstetric fistula in Bangladesh. Dhaka,. Engender Health 2003 Sep.

20. Vangeenderhuysen C PA, Ould el Joud D:: Obstetric fistulae: incidence estimates for sub-Saharan Africa.2001,73(1). Int J Gynaecol Obstet 2001, 73(1):65-66.

21. Danso KA, Martey J, Wall LL, Elkins TE: The epidemiology of genitourinary fistulae in Kumasi, Ghana, 1977-1992. International Urogynecology Journal 1996, 7(3):117-120.

22. Tebeu PM, De Bernis L, Doh AS, Rochat $\mathrm{CH}$, Delvaux T: Risk factors for obstetric fistula in the Far North Province of Cameroon. International Journal of Gynecology \& Obstetrics 2009, 107(1):12-15.

23. Melah G, Massa A, Yahaya U, Bukar M, Kizaya D, El-Nafaty A: Risk factors for obstetric fistulae in north-eastern Nigeria. Journal of Obstetrics and Gynaecology 2007, 27(8):819-823.

24. Holme A, Breen M, MacArthur C: Obstetric fistulae: a study of women managed at the Monze Mission Hospital, Zambia. BJOG: An International Journal of Obstetrics \& Gynaecology 2007, 114(8):10101017.

25. Rahman M, Al-Suleiman S, El-Yahia A, Rahman J: Surgical treatment of rectovaginal fistula of obstetric origin: a review of 15 years' experience in a teaching hospital. Journal of Obstetrics and Gynaecology 2003, 23(6):607-610.

26. Sefrioui O, Aboulfalah A, Taarji H, Matar N, El Mansouri A: Current profile of obstetrical vesicovaginal fistulas at the maternity unit of the University of Casablanca. In: Annales d'urologie: 2001; 2001: 276279.

27. Chew SS, Rieger NA: Transperineal repair of obstetric-related anovaginal fistula. Australian and New Zealand journal of obstetrics and gynaecology 2004, 44(1):68-71. 
28. Hosseini S, Roshan Y, Safarinejad M: Ureterovaginal fistula after vaginal delivery. The Journal of urology 1998, 160(3):829.

29. Ramsey K, lliyasu Z, Idoko L: Fistula Fortnight: innovative partnership brings mass treatment and public awareness towards ending obstetric fistula. International Journal of Gynecology \& Obstetrics 2007, 99:S130-S136.

30. Muleta M, Hamlin EC, Fantahun M, Kennedy RC, Tafesse B: Health and social problems encountered by treated and untreated obstetric fistula patients in rural Ethiopia. Journal of Obstetrics and Gynaecology Canada 2008, 30(1):44-50.

31. Browning A: The circumferential obstetric fistula: characteristics, management and outcomes. BJOG: An International Journal of Obstetrics \& Gynaecology 2007, 114(9):1172-1176.

32. Rieger N, Perera S, Stephens J, Coates D, Po D: Anal sphincter function and integrity after primary repair of third-degree tear: uncontrolled prospective analysis. ANZ journal of surgery 2004, 74(3):122-124.

33. Nafiou I, Idrissa A, Ghaichatou A, Roenneburg M, Wheeless C, Genadry RR: Obstetric vesico-vaginal fistulas at the National Hospital of Niamey, Niger. International Journal of Gynecology \& Obstetrics 2007, 99:S71-S74.

34. Husain A, Johnson K, Glowacki CA, Osias J, Wheeless Jr CR, Asrat K, Ghebrekidan A, Polan ML: Surgical management of complex obstetric fistula in Eritrea. Journal of Women's Health 2005, 14(9):839-844.

35. Wall LL, Karshima JA, Kirschner C, Arrowsmith SD: The obstetric vesicovaginal fistula: characteristics of 899 patients from Jos, Nigeria. American journal of obstetrics and gynecology 2004, 190(4):1011-1016.

36. Ya QL, Ouattara Z, Ouattara K: Traitement des fistules vésico-vaginales à l'hôpital de Kati: À propos de 34 cas. Médecine d'Afrique Noire 2000, 47(3):165-168.

37. Hilton P, Ward A: Epidemiological and surgical aspects of urogenital fistulae: a review of 25 years' experience in southeast Nigeria. International Urogynecology Journal 1998, 9(4):189-194.

38. Gessessew A, Mesfin M: Genitourinary and rectovaginal fistulae in Adigrat Zonal Hospital, Tigray, north Ethiopia. Ethiopian medical journal 2003, 41(2):123-130.

39. Harouna Y, Seibou A, Maikano S, Djambeidou J, Sangare A, Bilane S, Abdou H: La fistule vesicovaginale de cause obstetricale: enquete aupres de $\mathbf{5 2}$ femmes admises au village des fistuleuses. Médecine d'Afrique Noire 2001, 48:55-59.

40. Ampofo EK, Omotara B, Otu T, Uchebo G: Risk factors of vesico-vaginal fistulae in Maiduguri, Nigeria: a case-control study. Tropical doctor 1990, 20(3):138-139.

41. Onolemhemhen DO, Ekwempu C: An investigation of sociomedical risk factors associated with vaginal fistula in northern Nigeria. Women \& health 1999, 28(3):103-116.

42. Roka ZG, Akech M, Wanzala P, Omolo J, Gitta S, Waiswa P: Factors associated with obstetric fistulae occurrence among patients attending selected hospitals in Kenya, 2010: a case control study. BMC Pregnancy and Childbirth 2013, 13(1):1-7. 
43. Thaddeus S, Maine D: Too far to walk: maternal mortality in context. Social science \& medicine 1994 , 38(8):1091-1110.

44. Karateke A, Cam C, Ozdemir A, Guney B, Vatansever D, Celik C: Characteristics of obstetric fistulas and the need for a prognostic classification system. Archives of medical science: AMS2010, 6(2):253.

45. Browning A FW, Goh JT: The impact of surgical treatment on the mental health of women with obstetric fistula. An International Journal of Obstetrics \& Gynaecology 2007, 11(114):1439-1441.

46. Goh JT SK, Krause HG, Browning A, Akhter S:: Mental health screening in women with genital tract fistulae. An International Journal of Obstetrics \& Gynaecology 2005, Sep;112(9)::1328-1330.

47. Donnay F, Weil L: Obstetric fistula: the international response. The Lancet 2004, 363(9402):71-72.

48. Polan ML, Sleemi A, Bedane MM, Lozo S, Morgan MA: Obstetric fistula. 2016.

49. Velez A, Ramsey K, Tell K: The Campaign to End Fistula: What have we learned? Findings of facility and community needs assessments. International Journal of Gynecology \& Obstetrics 2007, 99:S143-S150.

50. Hinrichsen D, Richey C, Robey B, Muller F: Obstetric fistula: Ending the silence, easing the suffering. Info Reports 2004, 2.

51. de la Muerte PP, Materna-AMDD I: Report on the meeting for the prevention \& treatment of obstetric fistula. London, july 2001. 2010.

52. Wall L: The Second Meeting of the Working Group for the Prevention and Treatment of Obstetric Fistula. Addis Ababa: UNFPA 2002:1066-1074.

53. Bloomberg JH: Obstetric Fistula. INFO REPORTER 2004.

54. Lotze W: Strengthening African Peace Support Operations: Nine Lessons for the Future of the African Standby Force. Center for International Peace Operations, Policy Briefing 2013.

55. Capes T, Ascher-Walsh C, Abdoulaye I, Brodman M: Obstetric fistula in low and middle income countries. Mount Sinai Journal of Medicine: A Journal of Translational and Personalized Medicine 2011, 78(3):352-361.

56. Singh J, Gupta S, Khanna A, Sharma LS: Prevalence of Obstetric Fistula and Associated Factors in Rajasthan, India. Journal of Health Management 2019, 21(2):193-198.

57. Kulkarni R: Magnitude and determinants of chronic obstetric morbidities in Nasik District in Maharashtra. Indian Council for Medical Research 2007 2007:2007-2008.

58. Sagna ML, Hoque N, Sunil T: Are some women more at risk of obstetric fistula in Uganda? Evidence from the Uganda Demographic and Health survey. Journal of Public Health in Africa 2011, 2(2).

59. Gulati B, Unisa S, Pandey A, Sahu D, Ganguly S: Correlates of occurrence of obstetric fistula among women in selected States of India: an analysis of DLHS-3 data. Facts, views \& vision in ObGyn 2011, 3(2):121.

60. Wang S, Yang L, Shang L, Yang W, Qi C, Huang L, Xie G, Wang R, Chung MC: Changing trends of birth weight with maternal age: A cross-sectional study in Xi'an city of Northwestern China. BMC 
Pregnancy and Childbirth 2020, 20(1):1-8.

61. Swain D, Parida SP, Jena SK, Das M, Das H: Prevalence and risk factors of obstetric fistula: implementation of a need-based preventive action plan in a South-eastern rural community of India. BMC women's health 2020, 20(1):1-10.

62. Dimbuene ZT, Amo-Adjei J, Amugsi D, Mumah J, Izugbara CO, Beguy D: Women's education and utilization of maternal health services in Africa: a multi-country and socioeconomic status analysis. Journal of biosocial science 2018, 50(6):725-748.

63. Okoli C, Hajizadeh M, Rahman MM, Khanam R: Geographical and socioeconomic inequalities in the utilization of maternal healthcare services in Nigeria: 2003-2017. BMC Health Services Research 2020, 20(1):1-14.

64. Nathan LM, Rochat CH, Grigorescu B, Banks E: Obstetric fistulae in West Africa: patient perspectives. American Journal of Obstetrics and Gynecology 2009, 200(5):e40-e42.

65. Andargie AA, Debu A: Determinants of obstetric fistula in Ethiopia. African health sciences 2017, 17(3):671-680.

66. Defar A, Okwaraji YB, Tigabu Z, Persson LÅ, Alemu K: Distance, difference in altitude and socioeconomic determinants of utilisation of maternal and child health services in Ethiopia: a geographic and multilevel modelling analysis. BMJ open 2021, 11(2):e042095.

67. Gao X, Kelley DW: Understanding how distance to facility and quality of care affect maternal health service utilization in Kenya and Haiti: A comparative geographic information system study. Geospatial health 2019, 14(1).

68. Samuel O, Zewotir T, North D: Decomposing the urban-rural inequalities in the utilisation of maternal health care services: evidence from 27 selected countries in Sub-Saharan Africa. Reproductive Health 2021, 18(1):1-12.

69. Musaba MW, Ndeezi G, Barageine JK, Weeks A, Nankabirwa V, Wamono F, Semakula D, Tumwine JK, Wandabwa JN: Risk factors for obstructed labour in Eastern Uganda: A case control study. PloS one 2020, 15(2):e0228856.

70. Sohn M, Jung M: Effects of empowerment and media use by women of childbearing age on maternal health care utilization in developing countries of Southeast Asia. International Journal of Health Services 2020, 50(1):32-43.

71. Project WsD, EngenderHealth: Risk and resilience: Obstetric fistula in Tanzania: Women's Dignity Project; 2006.

72. Kasamba N, Kaye DK, Mbalinda SN: Community awareness about risk factors, presentation and prevention and obstetric fistula in Nabitovu village, Iganga district, Uganda. BMC pregnancy and childbirth 2013, 13(1):1-10. 